\title{
Implications for burn shock resuscitation of a new in vivo human vascular microdosing technique (microdialysis) for dermal administration of noradrenaline
}

Anders Samuelsson, Simon Farnebo, Beatrice Magnusson, Chris Anderson, Erik Tesselaar, Erik Zettersten and Folke Sjöberg

\section{Linköping University Post Print}

N.B.: When citing this work, cite the original article.

Original Publication:

Anders Samuelsson, Simon Farnebo, Beatrice Magnusson, Chris Anderson, Erik Tesselaar, Erik Zettersten and Folke Sjöberg, Implications for burn shock resuscitation of a new in vivo human vascular microdosing technique (microdialysis) for dermal administration of noradrenaline, 2012, Burns, (38), 7, 975-983.

http://dx.doi.org/10.1016/j.burns.2012.05.012

Copyright: Elsevier http://www.elsevier.com/

Postprint available at: Linköping University Electronic Press http://urn.kb.se/resolve?urn=urn:nbn:se:liu:diva- 85852 


\section{Implications for burn shock resuscitation of a new in vivo human vascular microdosing technique (microdialysis) for skin administration of noradrenaline}

Anders Samuelsson M.D. ${ }^{1,5}$ Simon Farnebo M.D. ${ }^{3,4}$, Beatrice Magnusson Ph.D. ${ }^{2,4}$, Chris Anderson M.D, Ph.D. ${ }^{2,4}$, Erik Tesselaar Ph.D. ${ }^{1,4}$, Erik Zettersten ${ }^{4}$ and Folke Sjöberg M.D, Ph.D. ${ }^{1,3,4 .}$

Departments of ${ }^{1}$ Anesthesiology and Intensive Care, ${ }^{2}$ Dermatology, and ${ }^{3}$ Hand and Plastic Surgery and Burns, Linköping University Hospital,

and

Departments of ${ }^{4}$ Clinical and Experimental Medicine, ${ }^{5}$ Medicine and Health Sciences, Division of drug research/anesthesiology, Faculty of Health Sciences, Linkoping University,

all at:

58185 Linköping, Sweden.

Corresponding author

Anders Samuelsson M.D,

Dept. of Intensive Care,

University Hospital,

58185 Linkoping, Sweden

Phone +46132236 79,

E-mail: anders.samuelsson@lio.se 


\section{Abstract}

Introduction: Skin has a large dynamic capacity for alterations in blood flow, and is therefore often used for recruitment of blood during states of hypoperfusion such as during burn shock resuscitation . However, little is known about the metabolic consequences seen in skin secondary to application of vasoactive drugs. The aims of this study were: to develop an in vivo, human

microdosing model based on microdialysis in skin; and to investigate the effects on blood flow and metabolism by local application of noradrenaline followed by nitroglycerin especially from the perspective of burn shock resuscitation. .

Method: Nine healthy volunteers each had two or three microdialysis catheters placed intradermally in the volar surface of the lower arm. After a stabilization period, the catheters were perfused with buffers containing noradrenaline 0.5 or $5 \mu \mathrm{g} / \mathrm{ml}$ for 60 minutes, and after a second period of equilibrium of 60 minutes, all catheters were perfused with buffer containing nitroglycerine $(0.5 \mathrm{mg} / \mathrm{ml})$. Changes in the blood flow in the skin were measured by laser Doppler imaging urea and ethanol retrodialysis . Simultaneous changes in tissue glucose, lactate, and pyruvate concentrations were recorded.

Results: Perfusing skin with noradrenaline and nitroglycerine induced appreciable changes in all variables studied, depending on time and dose. The changes in glucose and lactate concentrations correlated with the change in blood flow assessed by either laser Doppler imaging or urea clearance. The changes in glucose and lactate that were induced by vasoconstriction (noradrenaline) continued until vasodilatation was induced by nitroglycerine. Conclusion: Noradrenaline given by microdialysis in healthy volunteers induced reproducible and dose-dependent hypoperfusion and ischaemia with simultaneous metabolic consequences. 
Among these, we particularly note that: tissue glucose concentrations responded rapidly to hypoperfusion but remained considerably higher than zero, which suggests an energy-dependent deficiency in cellular uptake; and vasoconstriction remained after cessation of the noradrenaline perfusion, implicating vasospasm and a lack of autoregulatory capacity in skin. These findings are particularly interesting from the critical care perspective, when noradrenaline is used extensively for circulatory support. The metabolic consequences may be underestimated and our results suggest that further investigations are warranted. 


\section{Introduction}

Skin is the largest organ in the body; it is well-vascularised, densely innervated, and closely integrated in the immune system. It is also one of the most dynamic organs as far as changes in blood flow are concerned, which may range from close to zero during maximum vasoconstriction (as in shock or cold stress) to about $60 \%$ of cardiac output (CO) in maximal heat stress or hyperaemia [1]. Skin at basal blood flow (roughly 5\% of CO) has an increased lactate concentration and lactate:pyruvate ratio, indicating a partly non-oxidative metabolism; consequently it is a major source of lactate in states of hypoperfusion and reperfusion [2].

In burn injuries it is accepted that the skin, and particularly the wound, is the "motor" of various inflammatory, metabolic, and circulatory changes $[4,5]$.We showed in a previous study, in which we used microdialysis in both the injured and uninjured skin of burned patients, that there is local acidosis and a persistent lack of autoregulation of blood flow in the skin during fluid resuscitation. These changes were parallel to altered glucose homeostasis locally, possibly the result of cytopathic hypoxia [3, 6].

Both under normal conditions and in the intensive care unit (ICU), the metabolic effects, and effects on skin blood flow, of commonly-used vasoactive drugs are still largely unknown; however, they may be assumed to affect blood flow and local tissue metabolism. Noradrenaline is widely used, and several studies have indicated that it has direct effects on cell metabolism such as the inhibition of energy metabolism in human mononuclear cells [7], depressed hepatocellular function, and induced production of superoxide radicals with impairment of mitochondrial respiration [8].

The aim of this study was to develop a human "in vivo" skin model in healthy volunteers for investigations of metabolic effects of changes in blood flow (as shown by glucose, lactate, and pyruvate concentrations) induced by adrenergic vasoconstriction 
(noradrenaline given locally) followed by nitrous oxide (NO)-mediated dilatation by nitroglycerine. Both drugs were delivered locally into the skin through a microdialysis system; this was also used to assess the metabolic variables simultaneously. Changes in blood flow to the skin were measured in parallel by laser Doppler imaging, and urea[9] and ethanol clearance [10] by retromicrodialysis.

Our underlying hypotheses were that increasing vasoconstriction is accomplished by a skin infusion of therapeutic concentrations of noradrenaline through the microdialysis system. This leads to reduced skin blood flow and possibly signs of ischaemia, with simultaneous effects on metabolism. The vasoconstrictive effects on both flow and metabolism can be restored by NO-mediated vasodilatation if not preceded by a vascular autoregulatory escape induced by the ischaemia itself. Theoretically the established doses of noradrenaline that were suggested by previous investigators seemed high [11], so a tenth of the dose was also studied. Importantly, and to validate the actual dose of the drug being delivered to the tissue, we also measured the amount of noradrenaline going from the tissue into the dialysate.

\section{Subjects and methods}

\section{Microdialysis technique}

The microdialysis system consisted of CMA/107 pumps and CMA/70 microdialysis catheters with a shaft $60 \mathrm{~mm}$ long and a membrane $10 \mathrm{~mm}$ long (CMA, Microdialysis AB, Stockholm, Sweden). The shaft of the probe had an outer diameter of $0.6 \mathrm{~mm}$ and a molecular cut-off of $20 \mathrm{kDa}$. The perfusion fluid (perfusate) used was sterile Ringer's solution in which 20 $\mathrm{mmol} / \mathrm{L}$ and $5 \mathrm{mmol} / \mathrm{L}$ of urea and ethanol, respectively, were added by Apoteksbolaget $\mathrm{AB}$ (APL, Umeå, Sweden). Before each catheter was inserted, the skin was cleaned with 
chlorhexidine and alcohol (5 mg/ml, Fresenius Kabi, Uppsala, Sweden) and the skin anaesthetised with Xylocain ${ }^{\circledR}(10 \mathrm{mg} / \mathrm{ml}$, AstraZeneca) $0.2 \mathrm{ml}$ given intradermally.

In 4 volunteers two probes were inserted about $3 \mathrm{~cm}$ apart in the ventral skin of the forearm, and in the other 5 , three probes.

A venous cannula (Venflon $^{\mathrm{TM}}$ Pro1.2 $\times 32 \mathrm{~mm}$, Becton Dickinson AB, Helsingborg, Sweden) was used as an introducer, and was inserted intradermally. The probe was then inserted through the guide, after which the guide was withdrawn. Ultrasound measurements (Dermascan A, Sonotron AB, Sweden) confirmed that the depth of the probe was adequate, mean $(\mathrm{SD}) 0.78(0.23) \mathrm{mm}$. This is consistent with several other investigations [12-14].

\section{Subjects}

Nine healthy, non-smoking volunteers, 6 men and 3 women, mean (SD) age of 28 (6) years, participated in the study after giving informed consent.

Exclusion criteria were: dermatological problems, allergies, cardiovascular disease, or taking prescribed drugs. Subjects were asked to refrain from drinking any substance containing caffeine during the study. All were acclimatised to $22-23^{\circ} \mathrm{C}$ for 30 minutes before the study started. The subjects remained sitting with the arms at the level of the heart throughout the experiments. The study design conformed to the declaration of Helsinki and was approved by the Regional Ethics Committee for Human Research at Linköping University, Linköping, Sweden (M08-05).

\section{Study design}

Phase A (0-90 minutes) 
The microdialysis probes $(\mathrm{n}=23)$ were allowed to equilibrate for 90 minutes. Throughout the experiments the perfusion speed was set at $2 \mu \mathrm{l} /$ minute and samples (dialysate) were collected into prelabelled capped collection vials at 10 minute intervals.

Phase B (0-60 minutes)

Sixteen probes (in 9 subjects) were perfused with noradrenaline in Ringer's solution 0.005 $\mathrm{mg} / \mathrm{ml}$. Urea and ethanol were added to 9 of the probes.

Seven probes (in 5 subjects) were perfused with noradrenaline in Ringer's solution 0.0005 $\mathrm{mg} / \mathrm{ml}$ with urea and ethanol. All probes were perfused for 60 minutes.

Phase C (60-120 minutes)

A second equilibration period with perfusion fluid followed, but without the addition of vasoactive drugs (including urea and ethanol).

Phase D (120-180 minutes)

All probes were perfused with a perfusate containing nitroglycerine $0.5 \mathrm{mg} / \mathrm{ml}$ (AstraZeneca $\mathrm{AB}$, Sweden).

Phase E (180-200 minutes)

A third equilibration period followed, with only perfusion fluid (including urea and ethanol).

\section{Analysis of metabolites}

The microdialysis samples were analysed with a CMA 600 Microdialysis analyser (CMA, Microdialysis Research AB, Stockholm, Sweden) using enzymatic reagents and colorimetric measurements of the samples [15]. Concentrations of glucose, lactate, and pyruvate were assayed enzymatically by glucose-, L-lactate-, and pyruvate-oxidase techniques, respectively. Urea concentrations were calculated from the rate of breakdown of nicotinamide adenine dinucleotide (NADH). 


\section{Laser Doppler perfusion imaging}

A laser Doppler perfusion imaging technique (PIM 1.0, Lisca Development AB, Linköping, Sweden) was used to monitor blood flow in 8 probes (4 subjects) before the experiment (baseline), and at 5-minute intervals for a total of 300 minutes. To indicate "no perfusion", the biological zero signal from the laser Doppler was recorded at the end of the experiment by a temporary occlusion ( 2 minutes) of the arterial circulation to the limb by a blood pressure cuff.

The laser Doppler scanning system contained a low power He-Ne laser (1mW, $632 \mathrm{~nm}$ ), in which the beam was moved by a step motor device, which provided the scanning procedure over the surface of the skin. Doppler shifts in the backscattered light were detected and processed to generate an output signal, which is linearly proportional to tissue perfusion by blood in the upper $200-300 \mu \mathrm{m}$ of the skin. The head of the scanner was positioned $16 \mathrm{~cm}$ above the skin surface and set to scan an area $3 \times 3 \mathrm{~cm}$ at each experimental site and on each occasion. Each image format consisted of $64 \times 64$ measurement sites (medium resolution, high scan speed) with a distance of about $1 \mathrm{~mm}$ between each measurement point. The approximate time required for such an image to be recorded was about 1 minute. These settings included the skin area overlying the microdialysis catheter. Data were analysed using the manufacturer's software (LDPI win version 2.3, Patch Test Analysis 1.3). The mean blood perfusion was calculated from the perfusion values recorded within the region of interest positioned above the tip of the catheters in an area of roughly $1 \times 0.5 \mathrm{~cm}$.

\section{Assay of noradrenaline}

A high performance liquid chromatography system consisting of a P680 HPLC pump (Dionex), an automated sample injector ASI-100 (Dionex), an electrochemical detector DECADE (Antec Leydon) were used. The analytical column was an Aquasil C18 $250 \mathrm{~mm}$ x 
$4.6 \mathrm{~mm}$, particle size $5 \mu \mathrm{m}$, with a preceding matched guard column Aquasil C18 $10 \mathrm{~mm}$ x 4 $\mathrm{mm} \times 5 \mu \mathrm{m}$, both from Keystone Scientific. The temperature of the column was set at $23^{\circ} \mathrm{C}$ with an integrated oven from Dionex.

The mobile phase consisted of sodium 1-heptane-sulphonate $1 \mathrm{mmol}$, citric acid monohydrate $0.1 \mathrm{M}$, disodium-EDTA $0.05 \mathrm{mmol}$, and $5 \%$ acetonitrile (CAN); $\mathrm{pH}$ was adjusted to 2.7 with sodium hydroxide $1 \mathrm{M}$ before the ACN was added. The flow rate was set at $1.0 \mathrm{ml} / \mathrm{minute}$, the runtime was set at 15 minutes, and the detector at $+750 \mathrm{mV}$ (nA range) against the silver/silver chloride reference electrode. The volume of injection was $10 \mu 1$ for both standards and samples.

Chromatograms were measured using Chromeleon software from Dionex. Quantitation was achieved by comparison of peak area generated from the standard curve.

\section{Assay of ethanol concentration}

The alcohol dehydrogenase method was used to measure the ethanol concentration, as it is optimised for minute samples and low concentrations of ethanol. The concentration of the reaction product $\mathrm{NADH}$ is proportional to the concentrations of ethanol in the calibrators and samples. Absorbance of NADH was measured at a wavelength of $334 \mathrm{~nm}$ in 96-hole microtitre plates in a spectophotometer (Thermo Multiscan ${ }^{\circledR}$ Spectrum), and a non-linear calibration curve was used to evaluate the data. The lowest concentrations detected as significantly different from the blanks in $20 \mu \mathrm{l}$ samples was $0.025 \mathrm{mmol} / \mathrm{L}$. Coefficients of variation within or between assays were $4.1 \%$ and $6.4 \%$, respectively, in the measurement range of these samples. 


\section{Statistical analysis}

Four probes were excluded from the analysis because they were damaged or because they did not reach a stable equilibrium at the end of Phase A. To reduce the anticipated inter-subject differences, all data were normalised by subtracting the mean of the measured values at 70-90 minutes, and data are therefore presented as absolute change over time. Data from 90 minutes - that is, the beginning of the perfusion with the noradrenaline up to 300 minutes - were used for statistical analysis. 162 measurement points for each variable (glucose, lactate, urea, and pyruvate) was used for analysis. All variables were analysed using 2-way repeated measures analysis of variance (ANOVA) to test for the effects of time (phases B and D) and dose of drug (phase B only). For pyruvate too many values were missing for us to gain meaningful statistics, so pyruvate was excluded from the final analysis.

Correlations of the mean time-response data were calculated using Pearson's correlation coefficient. Each variable was correlated with laser Doppler imaging values and urea measurements, respectively. Only the data points during the period when the drug was being given were used for the correlation analyses (phases B and D).

Data are presented as mean (SEM). Probabilities of less than 0.05 were accepted as significant. All statistical analyses were made with the aid of GraphPad Prism version 5.02 for Windows (GraphPad Software, San Diego California USA, www.graphpad.com). 


\section{Results}

\section{Noradrenaline infusion (phase B)}

Perfusing the tissue with noradrenaline induced significant $(\mathrm{p}<0.0001)$ time-dependent changes in all variables analysed. There was an unacceptable variation in ethanol concentrations, which did not correlate with other changes and ethanol values were therefore excluded from further analysis.

Changes over time in urea, glucose, and lactate concentrations, and glucose:lactate ratio, are shown in Figure 2, (noradrenaline $0.5 \mu \mathrm{g} / \mathrm{ml}$ ) and, Figure 3, (noradrenaline $5 \mu \mathrm{g} / \mathrm{ml}$ ).

\section{Blood flow}

Laser Doppler showed a sudden drop with -0.11 (0.04) PU by 20 minutes. Perfusion decreased rapidly, followed by at a plateau at 60 minutes $-0.11(0.03)$ PU (Figure 1).

The urea concentration increased in a linear fashion, in parallel to, and independent of, the dose, with a maximum change at 60 minutes for both doses, 1,62 (0.36) $\mathrm{mmol} / \mathrm{L}$ (noradrenaline $0.5 \mu \mathrm{g} / \mathrm{ml}$ ) and $1.32(0.41)$ (noradrenaline $5 \mu \mathrm{g} / \mathrm{ml}$ ), respectively. There were no differences in tissue perfusion (laser Doppler/urea) between the doses of noradrenaline given.

\section{Metabolites}

The glucose concentration decreased early and rapidly, and thereafter more gradually. The lowest recorded value was at 60 minutes at $0.58(0.06) \mathrm{mmol} / \mathrm{L}$, (noradrenaline $0.5 \mu \mathrm{g} / \mathrm{ml}$; dose) and $-0.52(0.07) \mathrm{mmol} / \mathrm{L}$ (noradrenaline $5 \mu \mathrm{g} / \mathrm{ml}$; dose), respectively. 
Lactate increased in a sigmoid pattern and there was a slower increase in the lower dose $(0.5 \mu \mathrm{g} / \mathrm{ml})$, but the final concentrations reached at 60 minutes were similar, being $0.42(0.09) \mathrm{mmol} / \mathrm{L}$ and $0.45(0.08) \mathrm{mmol} / \mathrm{L}$, respectively.

The glucose:lactate ratio decreased rapidly during the noradrenaline infusion to $-1.66(0.24)$ and $-1.47(0.23) \mathrm{mmol} / \mathrm{L}$ (low and high dose, respectively) at 60 minutes.

\section{Second equilibrium phase (phase C) Blood flow}

After the noradrenaline infusion had been stopped, the laser Doppler values remained essentially unchanged for the next 50 minutes. Perfusion values were initially (at 60 minutes) $-0.11(0.03)$ and increased to $-0.08(0.03)$ at 120 minutes (Figure 1).

For those given the lower dose of noradrenaline $(0.5 \mu \mathrm{g} / \mathrm{ml})$ the concentration of urea in the dialysate decreased to $0.8(0.7) \mathrm{mmol} / \mathrm{L}$ above baseline. For the group that were given the higher dose, it remained unchanged for 50 minutes, and declined only during the final 10 minutes of this period to $1.11(1.34) \mathrm{mmol} / \mathrm{L}$ at 120 minutes.

\section{Metabolites}

During this phase glucose concentrations recovered slowly to $-0.33(0.13) \mathrm{mmol} / \mathrm{L}$ below baseline at 30 minutes in the group that had had the low dose of noradrenaline $(0.5 \mu \mathrm{g} / \mathrm{ml})$. For the group given the higher dose, the concentration remained unchanged throughout this phase, and reached $-0.45(0.08 \mathrm{mmol} / \mathrm{L})$ at 210 minutes.

The lactate concentration continued to increase, and plateaued after 30 minutes, whereas it declined during the final 10 minutes during this phase to $0.38(0.14) \mathrm{mmol} / \mathrm{L}$ at 120 minutes in subjects given the lower dose. For the group given the higher dose the pattern was similar, albeit more pronounced, and it remained at $0.67(0.16) \mathrm{mmol} / \mathrm{L}$ at 120 minutes. 
The lactate:glucose ratio remained unchanged for the first 30 minutes at -1.59 (0.22), whereafter it recovered to $-1.17(0.25)$ at 120 minutes for those given the lower dose. In the group given the higher dose the ratio continued to decrease until 110 minutes at -1.60 (0.25), improving only during the last 10 minutes to $-1.42(0.26)$ at the end of the equilibration period.

\section{Nitroglycerine infusion (phase D)}

Perfusing the tissue with nitroglycerine induced significant $((\mathrm{p}<0.0001)$ time-dependent changes in all variables.

\section{Blood flow}

Nitroglycerine induced an increase in perfusion after about 15 minutes. The initial response was slow but increased over time. The laser Doppler values went from an initial - 0.08 (0. 029) to $0.73(0.086)$ at 180 minutes (Figure 1$)$.

Urea values rapidly decreased in parallel and to the lowest value observed at 170 minutes, $-1.63(0.27) \mathrm{mmol} / \mathrm{L}$ and $-1.78(0.94) \mathrm{mmol} / \mathrm{L}$, after low and high doses of noradrenaline, respectively.

\section{Metabolites}

The glucose concentration increased rapidly to a value above baseline at 10 minutes in subjects exposed for the low dose of noradrenaline at $0.52(0.11) \mathrm{mmol} / \mathrm{L}$ at 180 minutes. For those not given the higher dose, it did not reach above baseline until after 40 minutes of perfusion with nitroglycerine at $0.07(0.11) \mathrm{mmol} / \mathrm{L}$, peaking at the end of perfusion at 0.26 $(0.12) \mathrm{mmol} / \mathrm{L}$. 
The lactate concentration decreased immediately in the subjects given the lower dose of noradrenaline, reaching baseline at the end of the perfusion period at $0.27(0.09)$ $\mathrm{mmol} / \mathrm{L}$. In the group given the higher dose of noradrenaline, lactate remained essentially unchanged for 40 minutes, decreasing only during the last 20 minutes to $0.24(0.08) \mathrm{mmol} / \mathrm{L}$ at 180 minutes; it did not therefore reach baseline during the period of perfusion of nitroglycerine.

The glucose:lactate ratio instantly reached nearly to the baseline value, and to the absolute baseline in 30 minutes, thereafter continuing to increase to $1.02(0.46) \mathrm{mmol} / \mathrm{L}$ in those given the low dose of noradrenaline. For those given the higher dose, the ratio increased more slowly, reaching above baseline only at the end of perfusion with nitroglycerine, at 0.40 (0.66) $\mathrm{mmol} / \mathrm{L}$.

\section{Concentrations of noradrenaline in the dialysate}

During infusion the concentration immediately plateaued at 120 minutes at $0.55(0.17) \mu \mathrm{M}$ (low dose) and 10.69 (2.24) $\mu \mathrm{M}$ (high dose), respectively. For the higher dose the dialysate values remained increased longer after cessation of perfusion. It gradually diminished until NO was perfused (Figure 5). Calculations are made from raw data, not normalized.

\section{Correlations between changes in perfusion as assessed by laser Doppler and urea clearance and changes in tissue concentrations of metabolites (glucose and lactate)}

There were significant correlations between all these variables during Phases B-D (Table 1). 


\section{Discussion}

Several of the findings of this study may have implications for the resuscitation of the critically ill burn patient. Firstly, microdosing of vasoactive drugs at a fixed rate and concentration through the microdialysis probe to the dermal layer in the skin of healthy volunteers induces reproducible physiological and metabolic time-dependent response patterns. Secondly, though previous studies of microdialysis have claimed the effect of physiological doses $(5 \mu \mathrm{g} / \mathrm{ml})$, the one-tenth dose of noradrenaline still induces appreciable vasoconstriction in the skin of healthy volunteers. Thirdly, normal skin exposed to the doses of noradrenaline used in this study seems to lack mechanisms to induce vasodilation by local intrinsic mediators resulting in sustained vasoconstriction with local ischaemia and serious metabolic disturbances. Fourthly, the data presented suggest that the present model may be used to assess local microvascular dose-response and effects of vasoactive substances in healthy volunteers and possibly also in patients, and may thereby aid the understanding of the effects both of the disease and the drugs given. As the tissue glucose concentrations during the later ischaemic period did not reach zero concentrations, the data suggest that during ischaemia that has been induced by a noradrenaline infusion, a defect in tissue cellular glucose uptake may be present. This is possibly the result of local depletion of energy, or insulin, or both. Fifthly, urea clearance by retrodialysis seems to be superior to the established methods such as laser Doppler and ethanol clearance in sensitivity and accuracy, and better reflects changes in skin blood flow in the low flow range as seen during vasoconstriction. The flow estimate provided by the urea technique pictures perfusion in the same catchment volume as the sampling for the metabolites. This simplifies the experimental design as it reduces the need to incorporate yet another technique to measure tissue blood flow. As 
anticipated, data obtained from ethanol clearance clearly indicated that this technique did not function at a perfusion rate of $2 \mu \mathrm{l} /$ minute in skin.

\section{Dose}

There have been many experiments with microdialysis in skin using noradrenaline to study the effects on recovery of, for example, manipulations in blood flow [16]. The dose of noradrenaline that we chose is well established [16-18] and is thought to be in the physiological and therapeutic ranges. However, we found long-lasting effects, including ischaemia and reduced glucose uptake, which implies that the dose was too high and that giving the drug to tissue with reduced blood flow might create a deposition of noradrenaline in the tissue. This was why a dose of one tenth was used for comparison. However, this dose was found also to have significant tissue effects as well, which comprised ischemia and hypoperfusion, why also the effects of even lower doses should be examined.

Similar pharmacodynamic effects based on blood flow were shown in another “in vivo" human skin model when the drug was given by iontophoresis. Quantification of local pharmacodynamic variables such as $\mathrm{ED}_{50}$ and Hill slope for the effect of blood flow is feasible [19]. If this is possible for both the effects of blood flow and for metabolic measurements as shown in the present model, complementary experiments seem warranted in the future.

\section{Auto regulatory escape - tissue protection}

Given the short half-life of noradrenaline we expected a fast release of the vasoconstriction when we turned from noradrenaline to buffer solutions. The microcirculation in general is regulated by an intrinsic metabolic system that balances sympathetic tone to maintain oxygen tension above critical values [20]. These mechanisms protect other vascular beds such as 
skeletal muscle and intestine during high sympathetic tone, and during exposure to pharmacological vasoconstriction $[20,21]$. Our results suggest that these protective systems at the doses used seem to be absent or dysfunctional; this was present with both doses, although less with the lower dose.

\section{Glucose}

Glucose concentrations in skin changed inversely to those of lactate during exposure to the drugThe parallel changes seen in glucose and lactate are consistent with previous investigations in non-insulin-dependent diabetic patients, which shows that cellular glucose uptake during acute ischaemia is initially dependent on the delivery of insulin and integrity of the insulin receptor, which is energy-dependent [22].

As ischaemia leads to local depletion of energy and insulin, it mediates activation of other pathways of glucose turnover that are different from that induced by insulin [22]. Our finding is interesting, because the mechanism of stress-induced peripheral insulin resistance is not completely understood and the present model may be useful in future investigations.

During perfusion with nitroglycerine, changes in both laser Doppler and urea showed a pronounced hyperaemic response during which the interstitial skin glucose concentrations initially remained low, indicating a glucose uptake impairment possibly due to a sustained microcirculatory ischemia reperfusion disturbance The late interstitial glucose increase, well above baseline concentrations, present despite anticipated unchanged blood values, is consistent with the findings in burn patients [6]. This suggests delivery exceeding metabolic capacity as seen in e.-g. cytopathic hypoxia. Such signs of cellular metabolic effects have not been recorded in other models of ischaemia such as tourniquet or skin flap $[23,24]$, which is why an association with noradrenaline seems plausible . Both noradrenaline 
$[7,8]$ and $\mathrm{NO}[25]$ have been associated with impaired mitochondrial function and altered energy metabolism.

\section{Urea}

Values for urea clearance showed considerable changes over time during the pharmacological interventions, and the close correlation with the alterations in the concentrations of metabolites, lactate, and lactate:glucose ratio, strongly supports the idea that urea adequately reflected the relative change in blood flow. This was further supported by the laser Doppler results. The continuing change in urea over time indicates that blood flow decreased further, even after laser Doppler technique had lost its sensitivity. This was further supported by the continuing change in concentrations of metabolic markers. Urea clearance, which also seemed to function at lower perfusion velocities $(0.3 \mu \mathrm{l} /$ minute $)$ presented advantages over other techniques for measuring blood flow such as ethanol clearance, as low perfusion rates increase recovery and the accuracy of the results, and also permit sampling of substances with low interstitial concentrations such as cytokines [26, 27]. These features make the urea clearance technique potentially interesting for further clinical use.

\section{Clinical values - tissue monitoring}

Our findings of local tissue changes in glucose homeostasis, which are not reflected systemically during either ischaemia or reperfusion, also highlight the fact that tissue glucose concentrations may not be mirrored by systemic changes. This emphasises that the use of local glucose monitoring has to be interpreted with caution $[28,29]$, which has also previously been stressed $[3,30]$. The discrepancy between local tissue-specific and systemic glucose responses to ischaemia and reperfusion suggests not only a future value for tissue monitoring, but also a better understanding of local tissue glucose homeostasis, particularly as 
this may affect the debate about different regimens and outcomes using intensive insulin treatment $[31,32]$.

From a critical care perspective this human in vivo skin model has the potential to be of use in the investigation of receptor sensitivity for vasoactive drugs during states of shock, not only burn injury induced but also such as during sepsis or trauma in humans [33], and mechanisms of peripheral insulin resistance, which have previously been difficult to investigate. At this point it has to be emphasised that our results are from healthy subjects and the relevance for critical illness is still to be confirmed.

\section{References}

1. Petersen LJ: Interstitial lactate levels in human skin at rest and during an oral glucose load: a microdialysis study. Clin Physiol 1999, 19:246-250.

2. Kellogg DL, Jr.: In vivo mechanisms of cutaneous vasodilation and vasoconstriction in humans during thermoregulatory challenges. J Appl Physiol 2006, 100:1709-1718.

3. Samuelsson A, Sjoberg F: The autors reply. Critical Care Medicin 2007, 35:14451446.

4. Arturson G: Forty years in burns research - the postburn inflammatory response. Burns 2000, 26:599-604. 
5. Rosenthal SR: Pharmacologically active and lethal substances from skin. Arch Environ Health 1965, 11:465-476.

6. Samuelsson A, Steinvall I, Sjoberg F: Microdialysis shows metabolic effects in skin during fluid resuscitation in burn-injured patients. Crit Care 2006, 10:R172.

7. Lunemann JD, Buttgereit F, Tripmacher R, Baerwald CG, Burmester GR, Krause A: Norepinephrine inhibits energy metabolism of human peripheral blood mononuclear cells via adrenergic receptors. Biosci Rep 2001, 21:627-635.

8. Rump AF, Klaus W: Evidence for norepinephrine cardiotoxicity mediated by superoxide anion radicals in isolated rabbit hearts. Naunyn Schmiedebergs Arch Pharmacol 1994, 349:295-300.

9. Farnebo S, Samuelsson A, Henriksson J, Karlander LE, Sjoberg F: Urea clearance: a new method to register local changes in blood flow in rat skeletal muscle based on microdialysis. Clin Physiol Funct Imaging 2009.

10. Hickner RC, Rosdahl H, Borg I, Ungerstedt U, Jorfeldt L, Henriksson J: Ethanol may be used with the microdialysis technique to monitor blood flow changes in skeletal muscle: dialysate glucose concentration is blood-flow-dependent. Acta Physiol Scand 1991, 143:355-356.

11. Leis S, Drenkhahn S, Schick C, Arnolt C, Schmelz M, Birklein F, Bickel A: Catecholamine release in human skin--a microdialysis study. Exp Neurol 2004, 188:86-93.

12. Krogstad AL, Jansson PA, Gisslen P, Lonnroth P: Microdialysis methodology for the measurement of dermal interstitial fluid in humans. Br J Dermatol 1996, 134:1005-1012. 
13. Anderson $\mathrm{C}$, Andersson $\mathrm{T}$, Wardell $\mathrm{K}$ : Changes in skin circulation after insertion of a microdialysis probe visualized by laser Doppler perfusion imaging. J Invest Dermatol 1994, 102:807-811.

14. Petersen LJ, Kristensen JK, Bulow J: Microdialysis of the interstitial water space in human skin in vivo: quantitative measurement of cutaneous glucose concentrations. J Invest Dermatol 1992, 99:357-360.

15. Lloyd B, Burrin J, Smythe P, Alberti KG: Enzymic fluorometric continuous-flow assays for blood glucose, lactate, pyruvate, alanine, glycerol, and 3hydroxybutyrate. Clin Chem 1978, 24:1724-1729.

16. Clough GF, Boutsiouki P, Church MK, Michel CC: Effects of blood flow on the in vivo recovery of a small diffusible molecule by microdialysis in human skin. $J$ Pharmacol Exp Ther 2002, 302:681-686.

17. Boutsiouki P, Clough GF: Modulation of microvascular function following lowdose exposure to the organophosphorous compound malathion in human skin in vivo. J Appl Physiol 2004, 97:1091-1097.

18. Wilson TE, Monahan KD, Short DS, Ray CA: Effect of age on cutaneous vasoconstrictor responses to norepinephrine in humans. Am J Physiol Regul Integr Comp Physiol 2004, 287:R1230-1234.

19. Tesselaar E, Henricson J, Jonsson S, Sjoberg F: A time-response model for analysis of drug transport and blood flow response during iontophoresis of acetylcholine and sodium nitroprusside. J Vasc Res 2009, 46:270-277.

20. Vallet B: Endothelial cell dysfunction and abnormal tissue perfusion. Crit Care Med 2002, 30(5 Suppl):S229-234. 
21. Nygren A, Thoren A, Ricksten SE: Vasopressors and intestinal mucosal perfusion after cardiac surgery: Norepinephrine vs. phenylephrine. Crit Care Med 2006, 34:722-729.

22. Niklasson M, Holmang A, Sjostrand M, Strindberg L, Lonnroth P: Muscle glucose uptake is effectively activated by ischemia in type $\mathbf{2}$ diabetic subjects. Diabetes 2000, 49(7):1178-1185.

23. Ostman B, Michaelsson K, Rahme H, Hillered L: Tourniquet-induced ischemia and reperfusion in human skeletal muscle. Clin Orthop Relat Res 2004(418):260-265.

24. Setala LP, Korvenoja EM, Harma MA, Alhava EM, Uusaro AV, Tenhunen JJ:

Glucose, lactate, and pyruvate response in an experimental model of microvascular flap ischemia and reperfusion: a microdialysis study. Microsurgery 2004, 24(3):223-231.

25. Protti A, Singer M: Bench-to-bedside review: potential strategies to protect or reverse mitochondrial dysfunction in sepsis-induced organ failure. Crit Care 2006, 10(5):228.

26. Sjogren F, Svensson C, Anderson C: Technical prerequisites for in vivo microdialysis determination of interleukin-6 in human dermis. $\mathrm{Br} J$ Dermatol 2002, 146(3):375-382.

27. Farnebo S, Lars-Erik K, Ingrid S, Sjogren F, Folke S: Continuous assessment of concentrations of cytokines in experimental injuries of the extremity. Int J Clin Exp Med 2009, 2(4):354-362.

28. Beardsall K, Ogilvy-Stuart AL, Ahluwalia J, Thompson M, Dunger DB: The continuous glucose monitoring sensor in neonatal intensive care. Arch Dis Child Fetal Neonatal Ed 2005, 90:F307-310. 
29. De Block C, Manuel YKB, Van Gaal L, Rogiers P: Intensive insulin therapy in the intensive care unit: assessment by continuous glucose monitoring. Diabetes Care 2006, 29:1750-1756.

30. Klonoff D: Subcutaneous continuous glucose monitoring in severe burn patients. Critical Care Medicin 2007, 35:1445.

31. Finfer S, Chittock DR, Su SY, Blair D, Foster D, Dhingra V, Bellomo R, Cook D, Dodek P, Henderson WR et al: Intensive versus conventional glucose control in critically ill patients. $N$ Engl J Med 2009, 360:1283-1297.

32. van den Berghe G, Wouters P, Weekers F, Verwaest C, Bruyninckx F, Schetz M, Vlasselaers D, Ferdinande P, Lauwers P, Bouillon R: Intensive insulin therapy in the critically ill patients. $N$ Engl J Med 2001, 345:1359-1367.

33. Silverman HJ, Penaranda R, Orens JB, Lee NH: Impaired beta-adrenergic receptor stimulation of cyclic adenosine monophosphate in human septic shock: association with myocardial hyporesponsiveness to catecholamines. Crit Care Med 1993, 21:31-39.

\section{Figures}


04/12/2012

24

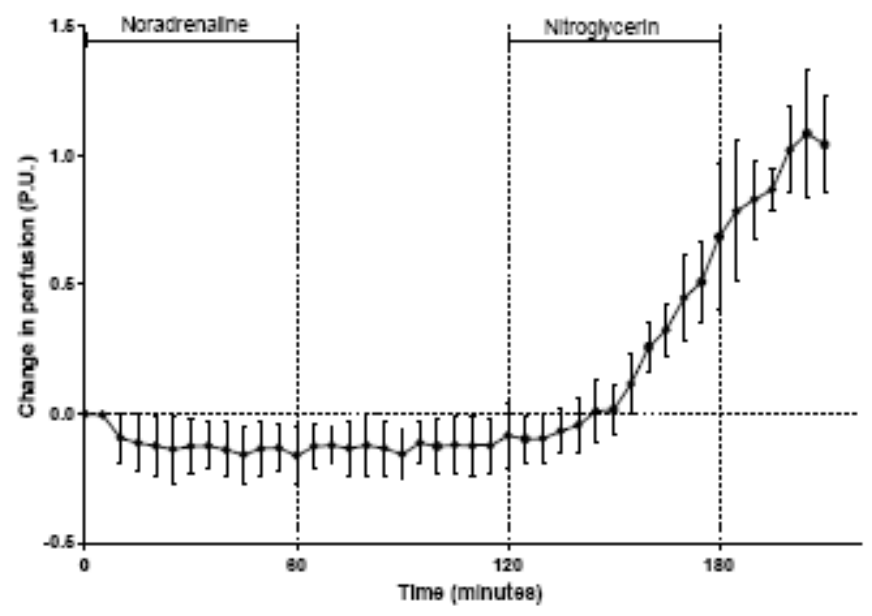

Fig 1

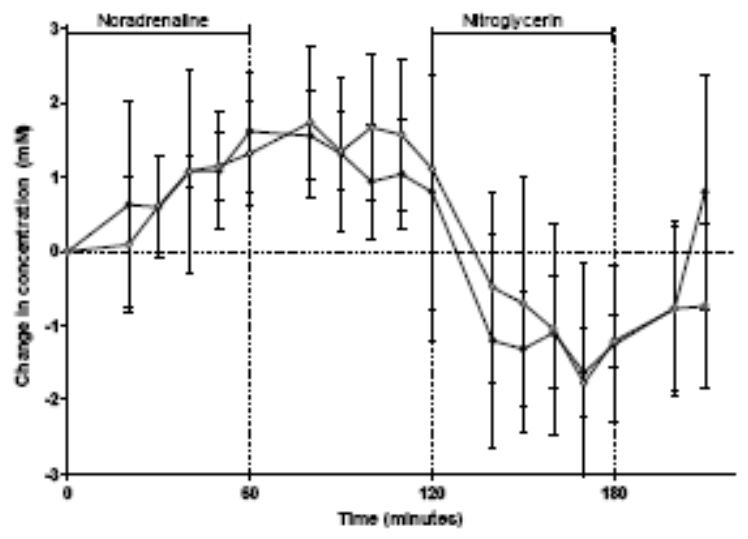

Figure 2 


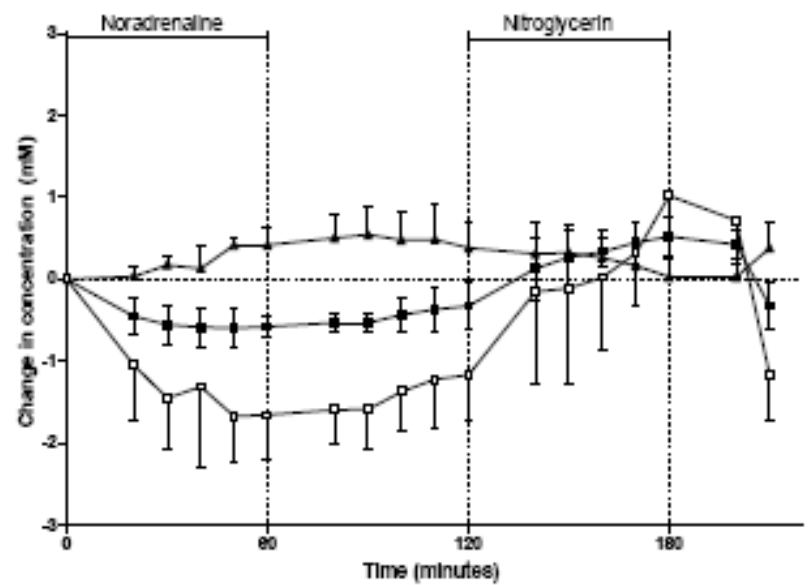

Figure 3

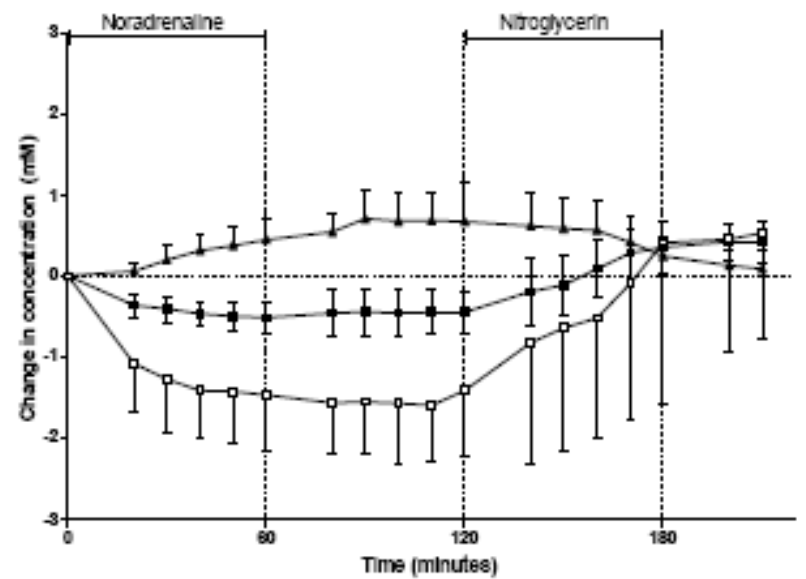

Figure 4 


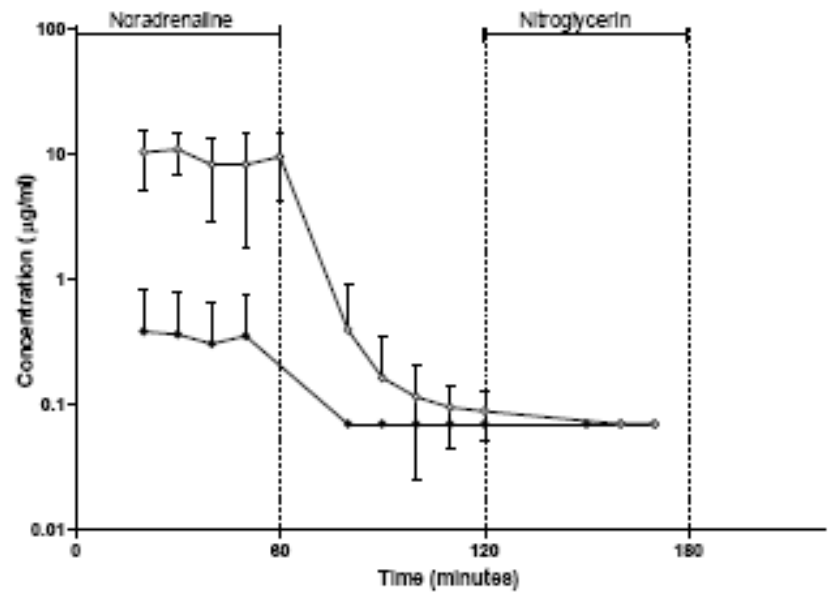

Figure 5

Table

\begin{tabular}{|llll|}
\hline Interaction & Metabolite & r value & p value \\
\hline Noradrenaline & Glucose & -0.3 & 0.2 \\
& Lactate & 0.8 & $<0.0001$ \\
& Glucose: lactate & & \\
& ratio & -0.63 & 0.03 \\
& & & \\
Nitroglycerine & Glucose & -0.88 & $<0.0001$ \\
& Lactate & 0.35 & 0.2 \\
& Glucose: lactate & & \\
ratio & -0.81 & $<0.0001$ \\
& & &
\end{tabular}

Table 1. 


\section{Legends to Figures}

Figure 1. Mean (SEM) absolute change in perfusion units measured by laser Doppler over time: 7 probes in 4 subjects $(\mathrm{p}<0.0001)$.

Figure 2. Mean (SEM) absolute change in urea over time: $0.5 \mu \mathrm{g} / \mathrm{ml}=$ grey line (6 probes in 3 subjects), and $5 \mu \mathrm{g} / \mathrm{ml}=$ black line ( 6 probes in 5 subjects $)(\mathrm{p}<0.0001)$.

Figure 3. Mean (SEM) absolute changes in metabolites: glucose=black boxes; lactate=black triangles; and glucose:lactate ratio=white triangles over time in subjects given $0.5 \mu \mathrm{g} / \mathrm{ml}$ noradrenaline (6 probes; 3 subjects ) during perfusion with noradrenaline and nitroglycerine $(\mathrm{p}<0.0001)$.

Figure 4.Mean (SEM) absolute changes in metabolites: glucose=black boxes; lactate=black triangles; and glucose:lactate ratio=white boxes over time during 
perfusion with noradrenaline and nitroglycerine in subjects given noradrenaline $5 \mu \mathrm{g} / \mathrm{ml}(13$ probes in 9 subjects $)(\mathrm{p}<0.0001)$.

Figure 5. Mean (SEM) absolute values of noradrenaline concentrations in the perfusate: $(0.5 \mu \mathrm{g} / \mathrm{ml}=$ black boxes $),(5 \mu \mathrm{g} / \mathrm{ml}=$ white boxes $)$ seen over time $(6$ and 5 probes in 4 subjects, respectively) $(\mathrm{p}<0.0001)$.

Table 1. Individual correlations between urea and metabolite data during pharmacological interventions phase B and D, respectively. 